\title{
Predictors of IDDM recurrence risk in offspring of Danish IDDM patients
}

\author{
T. Lorenzen ${ }^{1}$, F. Pociot ${ }^{1}$, L. Stilgren ${ }^{2}$, O.P. Kristiansen ${ }^{1}$, J. Johannesen ${ }^{1}$, P. B. Olsen ${ }^{3}$, A.Walmar $^{4}$, A. Larsen $^{5}$, \\ N. C. Albrechtsen ${ }^{4}$, P. C. Eskildsen ${ }^{6}$, O.O. Andersen ${ }^{2}$, J. Nerup ${ }^{1}$ and the Danish IDDM Epidemiology and \\ Genetics Group*
}

${ }^{1}$ Steno Diabetes Center, Gentofte, Denmark

${ }^{2}$ Hillerød Sygehus, County of Frederiksborg, Denmark

${ }^{3}$ Slagelse Sygehus, County of Vest-Sjælland

${ }^{4}$ Næstved Sygehus, County of Storstrøm

${ }^{5}$ Holbæk Sygehus, County of Vest-Sjælland

${ }^{6}$ Køge Sygehus, County of Roskilde, Denmark

Summary It has previously been observed that offspring of mothers with insulin-dependent diabetes mellitus (IDDM) have a lower risk of IDDM than offspring of IDDM affected fathers. To assess the offspring IDDM recurrence risk in a Danish populationbased study and to investigate parental and offspringrelated biological variables that might influence this risk, we identified 2726 IDDM probands and their 2826 offspring from a background population of 1.725 million people (33\% of the Danish population). Current age of probands was 20-65 years and their age at IDDM onset was 30 years or less. Sixtynine offspring $(2.4 \%)$ were affected with IDDM. The sex difference in the parental-offspring IDDM transmission rate was confirmed. The cumulative IDDM risk up to age 30 years was found to be significantly decreased in maternal offspring compared to paternal offspring $(2.3 \pm 0.6$ and $5.7 \pm 0.9 \%, \mathrm{RR}=$ $2.40,95 \%$ CI $1.30-4.47 ; p=0.004)$ only if parents were diagnosed with IDDM before birth of the offspring. However, due to the low number of diabetic offspring of probands diagnosed with IDDM after offspring birth, this observation needs to be confirmed in a larger population. In a subpopulation of the 2380 offspring, whose parents were all diagnosed with IDDM before offspring birth, the recurrence risk was significantly increased in offspring of male probands diagnosed up to age 17 years compared to offspring of fathers diagnosed at older ages $(8.5 \pm 1.8$ and $3.6 \pm 1.0 \%$; RR $=2.27,95 \%$ CI $1.21-4.25 ; p=$ $0.006)$. No such relation was found in maternal offspring. Using the Cox proportional hazards model on this offspring subpopulation we found that paternal age at IDDM onset was the only statistically significant predictor of IDDM recurrence risk. Our findings may be important for counselling families in which one parent has IDDM. [Diabetologia (1998) 41: 666-673]

Keywords IDDM, epidemiology, offspring, recurrence risk, sex difference, prediction, cumulative risk, Cox proportional hazards model.
Received: 14 July 1997 and in revised form: 29 December 1997

Corresponding author: T. Lorenzen, M.D., Steno Diabetes Center, Niels Steensens Vej 2, DK-2820 Gentofte, Denmark Abbreviations: IDDM, Insulin-dependent diabetes mellitus; $\mathrm{RR}$, risk ratio; $\mathrm{CI}$, confidence interval; $\mathrm{SD}$, standard deviation; $\mathrm{SE}$, standard error.

* The following members of the Danish IDDM Epidemiology and Genetics Group have also contributed to the present study: Bernhard Enk (Nykøbing Falster), Finn Mølgaard Hansen (Nastved), Henning Juhl (Slagelse), Henning Bakgaard Laursen (Kalundborg), Karsten Sølling (Holbak), Steen Vadstrap (Nykøbing Falster).
Insulin-dependent diabetes mellitus (IDDM) is a serious chronic disorder caused by an immune mediated selective destruction of the insulin-producing beta cells in the pancreas. Genetically, IDDM is a complex disorder. In previous studies the average rate of IDDM recurrence risks in offspring up to age 20 years was approximately $5 \%$ [1-6]. In a recent study on Danish long-term surviving IDDM patients [7] it was found that the IDDM risk in their offspring up to age 34 years was $6.3 \%$. Genes in the HLA complex constitute the major IDDM susceptibility factor but also genes outside this region confer susceptibility $[8,9]$. Although genetic factors are thought to play a major role in the aetiology of IDDM the pa- 
tho-genetic process seems to be also determined by environmental factors [10].

Epidemiological studies may be helpful for increasing our understanding of IDDM as well as being important sources for genetic studies. The Danish population is approximately 5.2 million; the prevalence of IDDM in Denmark is $0.4 \%$ [9] and the mean incidencerates in Danish representative subpopulations in the age groups $0-29$ years and over 29 years is 13.2 and $8.2 \cdot 100000^{-1} \cdot$ year $^{-1}$, respectively $[11,12]$.

A recent Danish nationwide population-based study of the familial aggregation of IDDM [13] found that diabetic offspring of IDDM parents were significantly more likely to have an affected father than an affected mother. Similar observations have been made in other studies [14-17]. In order to avoid ascertainment bias, the optimal study design, however, is a follow-up design with calculation of the cumulative IDDM risk (number of IDDM cases per total number of offspring-years at risk) in offspring of families ascertained through IDDM in the parental generation. A recent Finnish nationwide register-based study [6] found that offspring of IDDM affected fathers had a higher IDDM risk compared to offspring of IDDM affected mothers. Furthermore, a number of previous non-Scandinavian studies $[2-5,18]$ in which the probands were ascertained from the parental generation supported this gender difference in recurrence risk of IDDM in offspring. However, most of these studies were performed on small and selected populations. From two recent studies on different patient populations from the Joslin Diabetes Clinic, relationships between parental age of IDDM onset and the recurrence risk in their offspring was reported $[4,5]$. It was also shown that the risk of IDDM in offspring of IDDM mothers was significantly increased in offspring born to mothers younger than 25 years of age compared to older mothers $[4,5,19]$. Other studies have shown that the IDDM recurrence risk in offspring was influenced by gender and birth order of the offspring $[6,14,17]$. The aim of the present study was to assess the recurrence risk of IDDM in 2826 offspring of a population of 2726 adult Danish IDDM patients, and to identify and characterise parental- and offspring-related biological variables that might influence the recurrence risk of IDDM. The present study is a non-concurrent prospective study, i. e. the outcomes of interest occurred in the past [20].

\section{Subjects and methods}

Background population. In Denmark an annual census is performed [21], thereby allowing an exact demographic description of the population. The populations of the five counties: Copenhagen, Frederiksborg, Roskilde, Vest-Sjælland and Storstrøm, respectively, were chosen as a background population. These areas are inhabited by a total of 1.725 million people, i.e. $33 \%$ of the Danish population.
Study population and methods. No central registration of patients with IDDM takes place in Denmark. In the present study we intended to identify all Caucasian IDDM patients of the survey area aged between 20 and 65 years on continuous insulin treatment since the time of diagnosis.

The Steno Diabetes Center (SDC) is an integrated part of the public Danish Health Care serving Copenhagen County as a primary and secondary referral centre for IDDM. From previous incidence studies [11, 12] of IDDM in Copenhagen County we know that only about $1 \%$ of IDDM cases are not referred to the SDC, either at presentation or within a few weeks thereafter, for lifelong outpatient follow-up. This referral pattern has not changed, with the exception that about half the cases of newly diagnosed IDDM patients below the age of 15 years during the last decade have been referred to the department of paediatrics at Glostrup Hospital. By the age of 18 years these patients are referred to the SDC for follow-up.

Outside Copenhagen County the referral pattern is different; all hospital-based regional diabetes care units participated and all 701 general practitioners (GPs) were asked to identify their IDDM patients fulfilling the inclusion criteria of the study. Seventy-two percent of the GPs co-operated and identified 118 patients, of these 71 were included in the study.

Extrapolating from the 118 patients identified through the GPs we could calculate that only 165 (5\% of the total) patients in total fulfilling the inclusion criteria were followed by GPs and not by hospital-based diabetes care units, since the nonparticipating GPs did not differ from the participating GPs in their way of running the clinics and none are known to have a special interest in diabetes care. That this does not significantly influence the study is obvious. This may be further supported by the fact that the prevalence of familial IDDM was similar in hospital-identified (17.5\%) and GP-identified cases $(18.2 \%)$.

There is no other completely independent source for ascertainment validation appropriate for this study. The coding of IDDM diagnoses is contaminated with insulin-treated non-insulin-dependent diabetic patients in the National Central Registry of Discharge Diagnoses, and for the same reason insulin prescriptions do not provide valid information either.

Information on age at IDDM onset and insulin treatment was obtained from the medical records of the identified IDDM patients aged between 20 and 65 years. Those fulfilling our inclusion criteria were asked to complete a questionnaire. If no response was received a second questionnaire was sent. If questionnaires were returned incomplete, further information was obtained by telephone interview. The questionnaires requested information on: Age and sex of all biological offspring and if any of these were deceased and/or had been diagnosed with IDDM, their age at the time of that event.

In total 3408 (1852 males and 1556 females; $p<0.001)$ potential probands were identified. Of these, $2824(82.9 \%)$ supplied information for the study. Ninety-eight $(2.9 \%)$ patients gave incomplete information and were not included in the analyses. Of the 3408 patients identified for the study, 2726 probands (1422 males and 1304 females; $p=0.1$ ) were included. Hence, the final participation rate was $80 \%$. However, female probands had a higher participation rate than male probands ( 84 vs $77 \% ; p<0.01$ ).

The female probands of the study population with offspring were pregnant during the period 1953-1995. In Denmark obstetric care for pregnant diabetic women is centralised and has followed national guidelines since 1946 [22, 23].

The study was approved by the ethics committee of the Counties of Copenhagen, Roskilde, Frederiksborg, Vest-Sjælland and Storstrøm and by the Danish Registertilsyn. Informed consent was obtained from all included probands. 
Table 1. Characterisation of all the included probands studied and age at time of offspring birth according to IDDM status at time of offspring birth

\begin{tabular}{llll}
\hline & Total & Males & Females \\
\hline$n$ & 2726 & 1422 & 1304 \\
Age (years) & $38.4 \pm 11.5$ & $38.9 \pm 11.6$ & $37.9 \pm 11.4$ \\
Age at onset (years) & $16.4 \pm 7.9$ & $17.2 \pm 7.9^{\mathrm{a}}$ & $15.5 \pm 7.7^{\mathrm{a}}$ \\
IDDM duration (years) & $22.0 \pm 11.9$ & $21.7 \pm 11.9$ & $22.4 \pm 11.7$ \\
Number of offspring & 2826 & 1541 & 1285 \\
Offspring per proband & 1.04 & $29.3 \pm 5.0^{\mathrm{a}}$ & 0.99 \\
Mean age at time of offspring birth (years) & $27.8 \pm 5.1$ & $568(40 \%)$ & $26.1 \pm 4.7^{\mathrm{a}}$ \\
Probands with no offspring & $1101(40 \%)$ & $533(41 \%)$ \\
\hline
\end{tabular}

\begin{tabular}{lll} 
& IDDM before offspring birth (2380 deliveries) & IDDM after offspring birth (382 deliveries) \\
\hline Males & $29.9 \pm 4.5^{\mathrm{b}}$ & $24.1 \pm 2.8$ \\
Females & $26.9 \pm 4.6^{\mathrm{b}}$ & $22.4 \pm 2.8$ \\
\hline
\end{tabular}

${ }^{\mathrm{a}} p_{\mathrm{c}}<0.001$. All other $p_{\mathrm{c}}$-values for comparisons between female and male probands $>0.4$

${ }^{\mathrm{b}} p<0.001$

Statistical analyses. A database of the 2726 included probands and their 2826 offspring was established using the PARADOX (version 4.5) software package (Borland, Scotts Valley, CA). Calculations and statistical analyses of the data were performed using the MICROSOFT EXCEL (version 7.0) (Microsoft Corporation, Redmond, WA) and the BMDP DYNAMIC (version 7.0). Demographic data are expressed as mean \pm SD. The two-tailed Student's $t$-test was used to evaluate statistical differences in means for continuous variables. For independent categorical variables, the chi-square test was used to compare proportions. The recurrence risks of IDDM in offspring were calculated for each age (expressed in years) as the number of cases per total number of offspring-years at risk using a standard life-table method \pm SE. The cumulative risk was calculated by addition of the risk values from the time of birth up to several different ages. Statistical comparisons of life-tables were performed using the Mantel-Cox test for estimating significance. Cox proportional hazards stepwise regression analyses were used to investigate the significance of several variables on cumulative recurrence risk. Relative risks (RR) and $95 \%$ confidence intervals (CI) were estimated when adjusting for covariates. The level of statistical significance was chosen as 0.05 (two-tailed). When multiple comparisons were performed between groups, $p$-values were corrected by the number of comparisons $\left(p_{\mathrm{c}}\right)$.

\section{Results}

The characteristics of the 2726 probands are summarised in Table 1. The mean age at the time of diagnosis in female and male probands, respectively was $15.5 \pm 7.7$ and $17.2 \pm 7.9$ years $\left(p_{\mathrm{c}}<0.001\right)$ not different from the corresponding median ages of IDDM onset of 17 years and 15 years. The IDDM duration in the probands was similar in males and females while the mean age at the time of offspring birth was significantly higher in male probands $\left(p_{\mathrm{c}}<0.001\right)$. This difference in mean age at offspring birth was however, only significant in probands diagnosed with IDDM before offspring birth (Table 1), probably due to the low number of deliveries in the other group. The 2726 probands had a total of 2826 off- spring with no significant difference in the mean number of paternal, as opposed to maternal offspring $\left(p_{\mathrm{c}}>0.4\right)$. Five hundred and sixty-eight male probands (40\%) and 533 female probands (41\%) had no offspring; however, stratifying the probands according to current age revealed that $79 \%$ of the probands aged above 40 years had at least one offspring with no significant difference between male and female probands (data not shown). Among these probands the mean number of offspring per male and female proband was 2.0 and 1.8, respectively $(p=0.3)$.

Forty-four of the 1422 male probands $(3.1 \%)$ and 22 of the 1304 female probands $(1.7 \%)$ had at least 1 IDDM affected offspring $(p=0.02)$. One male proband had 3 offspring with IDDM and another male proband had 2 IDDM affected offspring.

It was not possible to obtain information on current age in 64 of the 2826 offspring $(2.3 \%)$. Table 2 characterises the 2380 (84\%) offspring (1209 males, 1161 females, 10 of unknown gender) of probands diagnosed with IDDM before the time of delivery of the offspring in question. Table 2 characterises the 382 (14\%) offspring (206 males, 173 females, 3 of unknown gender) of probands diagnosed after offspring birth. In both groups there were no significant gender differences between the diabetic offspring, either in offspring of male nor of female probands. A significant positive birth order effect on IDDM prevalence was seen in offspring of female probands diagnosed with IDDM prior to offspring birth $\left(p_{\mathrm{c}}<0.001\right)$. The number of offspring per proband was significantly reduced in offspring of both male and female probands diagnosed with IDDM before the birth of the first offspring compared to probands diagnosed with IDDM after the birth of all their offspring ( 0.8 vs 1.9 in females; $p<0.0001$ and 1.0 vs 1.7 in males; $p=$ $0.005)$. No difference was found in mean current age between the two groups of probands diagnosed with IDDM before, rather than after offspring birth ( $45.4 \pm 10.1$ vs $45.5 \pm 10.5$ years; $p>0.5)$. 
Table 2. Characterisation of the 2380 offspring of parents diagnosed with IDDM before and after offspring birth

\begin{tabular}{|c|c|c|c|c|}
\hline & \multicolumn{2}{|l|}{ IDDM offspring } & \multicolumn{2}{|c|}{ Non-diabetic offspring } \\
\hline & IDDM in father & IDDM in mother & IDDM in father & IDDM in mother \\
\hline \multicolumn{5}{|l|}{ Before } \\
\hline$n$ & 42 & 13 & 1326 & 999 \\
\hline Sex (m/f/unknown) & $22 / 20 / 0$ & $7 / 6 / 0$ & $675 / 651 / 0$ & $505 / 484 / 10$ \\
\hline Age & $22.3 \pm 7.5$ & $21.3 \pm 5.5$ & $14.0 \pm 10.1$ & $14.8 \pm 10.7$ \\
\hline $\begin{array}{l}\text { Age at IDDM onset (years) } \\
- \text { in male offspring } \\
- \text { in female offspring }\end{array}$ & $\begin{array}{l}9.8 \pm 6.2 \\
11.1 \pm 6.7 \\
8.4 \pm 5.4\end{array}$ & $\begin{array}{l}10.0 \pm 4.4 \\
10.4 \pm 5.5 \\
9.5 \pm 3.1\end{array}$ & $\begin{array}{l}- \\
- \\
-\end{array}$ & $\begin{array}{l}- \\
- \\
-\end{array}$ \\
\hline Observation time (years) & 392 & 130 & 18474 & 14063 \\
\hline $\begin{array}{l}\text { IDDM prevalence } \\
\text { 1. born offspring } \\
\text { 2. born offspring } \\
\text { 3. born offspring } \\
\text { 4. born offspring }\end{array}$ & $\begin{array}{l}3.0 \%(21 / 689) \\
3.0 \%(15 / 508) \\
3.8 \%(5 / 130) \\
3.1 \%(1 / 32)\end{array}$ & $\begin{array}{l}1.4 \%(8 / 561) \\
0.8 \%(2 / 348) \\
1.3 \%(1 / 80) \\
13.3 \%(2 / 15)^{\mathrm{a}}\end{array}$ & $\begin{array}{l}- \\
- \\
- \\
-\end{array}$ & $\begin{array}{l}- \\
- \\
- \\
-\end{array}$ \\
\hline \multicolumn{5}{|l|}{ After } \\
\hline$n$ & 5 & 9 & 158 & 210 \\
\hline Sex (m/f/unknown) & $1 / 4 / 0$ & $7 / 2 / 0$ & $87 / 70 / 1$ & $111 / 97 / 2$ \\
\hline Age (years) & $27.7 \pm 8.8$ & $32.5 \pm 3.7$ & $25.5 \pm 9.3$ & $22.4 \pm 2.7$ \\
\hline $\begin{array}{l}\text { Age at IDDM onset (years) } \\
- \text { in male offspring } \\
- \text { in female offspring }\end{array}$ & $\begin{array}{l}15.5 \pm 6.2 \\
20.0 \pm 0.0 \\
14.6 \pm 8.6\end{array}$ & $\begin{array}{l}13.2 \pm 8.5 \\
14.3 \pm 9.3 \\
9.5 \pm 5.0\end{array}$ & $\begin{array}{l}- \\
- \\
-\end{array}$ & $\begin{array}{l}- \\
- \\
-\end{array}$ \\
\hline Observation time (years) & 93 & 137 & 3523 & 5397 \\
\hline $\begin{array}{l}\text { IDDM prevalence } \\
\text { 1. born } \\
\text { 2. born }\end{array}$ & $\begin{array}{l}4.1 \%(5 / 121) \\
-\end{array}$ & $\begin{array}{l}4.2 \%(6 / 143) \\
4.2 \%(3 / 72)\end{array}$ & $\begin{array}{l}- \\
-\end{array}$ & $\begin{array}{l}- \\
-\end{array}$ \\
\hline
\end{tabular}

${ }^{\mathrm{a}} p_{\mathrm{c}}<0.001$ for a birth order effect on the IDDM prevalence in offspring of female probands. All other $p_{\mathrm{c}}$-values for comparisons between paternal in respect to maternal offspring $>0.05$.

All $p_{c}$-values $>0.05$ for comparisons between paternal in respect to maternal offspring

Table 3. IDDM incidence rate per 10000 offspring observation years stratified according to age at diagnosis of IDDM (only offspring of parents diagnosed with IDDM before offspring birth)

\begin{tabular}{|c|c|c|c|c|}
\hline $\begin{array}{l}\text { Age at diagnosis } \\
\text { in probands }\end{array}$ & $\begin{array}{l}\text { Number of IDDM } \\
\text { affected offspring }\end{array}$ & $\begin{array}{l}\text { Offspring } \\
\text { observation years }\end{array}$ & $\begin{array}{l}\text { Number of affected offspring } \\
\text { per } 10000 \text { offspring years }\end{array}$ & $95 \%$ CI \\
\hline \multicolumn{5}{|l|}{ Males } \\
\hline $0-7$ & 8 & 1997 & 40.1 & $12.6-68.4$ \\
\hline $8-15$ & 14 & 4626 & 30.3 & $14.3-45.7$ \\
\hline $16-23$ & 13 & 6842 & 19.0 & $8.7-29.3$ \\
\hline 24-30 & 7 & 5401 & 13.0 & $1.4-24.6^{\mathrm{a}}$ \\
\hline \multicolumn{5}{|l|}{ Females } \\
\hline $0-7$ & 2 & 1763 & 11.3 & $-4.4-27.0$ \\
\hline $8-15$ & 4 & 5031 & 8.0 & $1.7-15.7$ \\
\hline $16-23$ & 3 & 5020 & 6.0 & $-7.8-12.7$ \\
\hline 24-30 & 4 & 2379 & 16.8 & $3.4-33.3$ \\
\hline
\end{tabular}

${ }^{\mathrm{a}} p=0.08$ for a decreasing IDDM incidence rate in paternal offspring

The cumulative recurrence risk of IDDM in offspring was calculated. Sixty-nine of the 2826 offspring $(2.4 \%)$ were diagnosed with IDDM and only one of those was diagnosed after age 30 years (male offspring of female proband, age at onset 33 years). In offspring of all probands the cumulative IDDM risk was $4.7 \pm 0.7 \%$ up to age 30 years and distinguishing between offspring of males and females, the risk was $5.7 \pm 0.9$ and $3.4 \pm 1.0 \%$, respectively, up to age 30 years $(\mathrm{RR}=1.92,95 \%$ CI $1.13-3.25 ; p=0.01)$. In the offspring whose parents were diagnosed with IDDM before offspring birth, IDDM had developed in 42 paternal offspring during 18866 offspring observation years and in 13 maternal offspring during 14193 offspring observation years. In this subpopulation the cumulative recurrence risks up to age 30 years (Fig. 1) in offspring of males rather than females were $5.7 \pm 0.9$ and $2.3 \pm 0.6 \%$, respectively $(\mathrm{RR}=2.40,95 \% \mathrm{CI} 1.30-4.47 ; p=0.004)$. In the offspring of probands diagnosed with IDDM after off- 


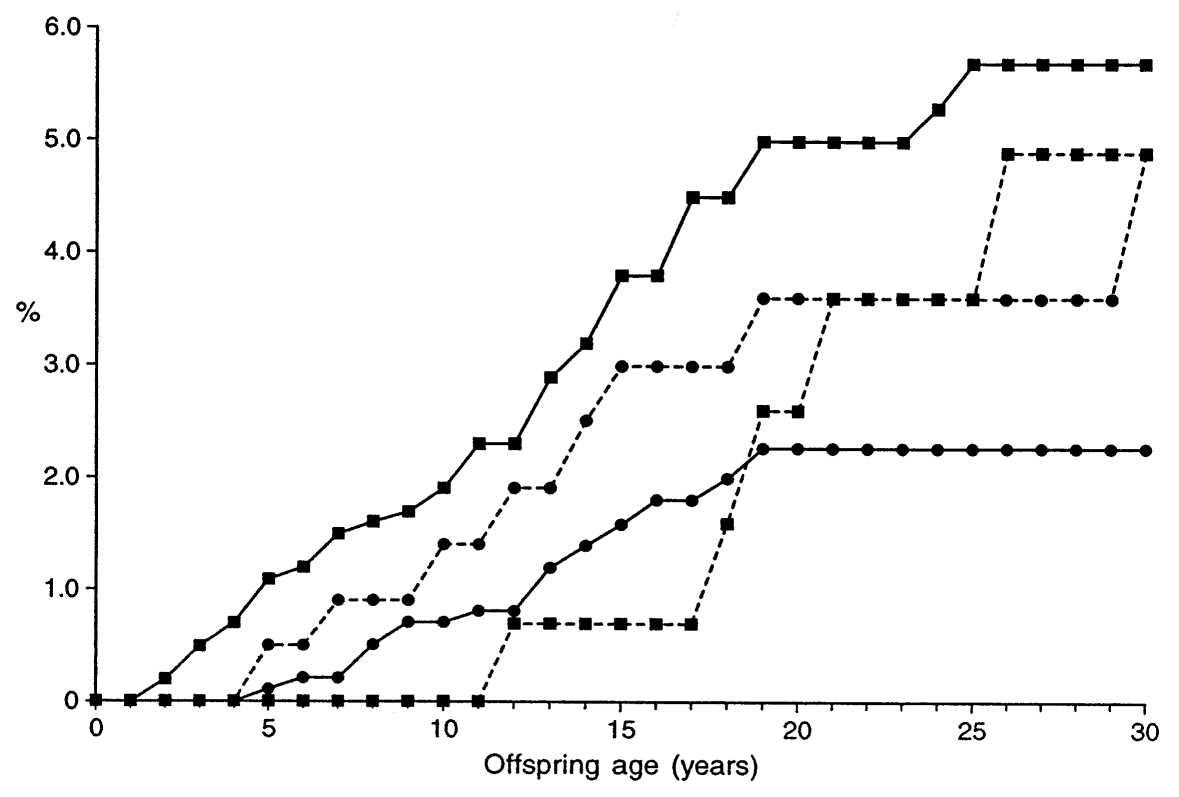

Fig.1. Cumulative IDDM recurrence risk in offspring of IDDM parents according to IDDM status at the time of offspring birth

- Female probands diagnosed before offspring birth (14193 obs. years, IDDM in 13)

- Male probands diagnosed before offspring birth (18866 obs. years, IDDM in 42)

--- Female probands diagnosed after offspring birth (5534 obs. years, IDDM in 9)

-- - Male probands diagnosed after offspring birth (3616 obs. years, IDDM in 5)

$p=0.004$ for comparison of IDDM cumulative recurrence risks between offspring of male, rather than female probands diagnosed before offspring birth. All other $p$-values $>0.05$ for comparisons between the life-tables

spring birth, IDDM had developed in 5 offspring of males and 9 offspring of females during 3616 and 5534 offspring observation years, respectively. The cumulative recurrence risks up to age 30 years were identical, i.e. $4.9 \pm 2.2$ and $4.9 \pm 1.8 \%$ in offspring of male and female probands, respectively $(p>0.9)$. In offspring of female probands we found a relative IDDM risk of $1.75,95 \%$ CI $0.72-4.25$ in offspring of mothers diagnosed with IDDM after offspring birth as compared to offspring of mothers diagnosed with IDDM prior to offspring birth. This difference, however, was not significant $(p=0.2)$ with the available number of maternal offspring IDDM cases. In paternal offspring the corresponding relative risk was $1.21,95 \%$ CI $0.61-2.64 ; p=0.7$.

In order to avoid a possible confounding from differences in parental IDDM status at the time of pregnancy, we have chosen to restrict the following analyses to the 2380 offspring whose parents were all diagnosed with IDDM before offspring birth. The incidence rates of IDDM in offspring, according to the probands age of IDDM onset, are shown in
Table 3. These data suggest that offspring of male probands diagnosed at an early age have an increased IDDM recurrence risk. A possible influence of parental age of IDDM onset on the cumulative IDDM recurrence risk in offspring was evaluated by calculation of this risk according to the median age of IDDM onset in male and female probands of 17 and 15 years, respectively. When we use these cut-off points in the analyses, the numbers of offspring observation-years (the denominator of the life-table analyses) in the subgroups are of the same magnitude giving the best power for the detection of differences between the subgroups. This analysis revealed (Fig. 2) that the cumulative IDDM risk up to age 30 years in offspring of male probands diagnosed up to or later than 17 years was $8.5 \pm 1.8$ and $3.6 \pm 1.0 \% ; \mathrm{RR}=2.27,95 \%$ CI $1.21-4.25 ; p=0.006$. In offspring of female probands diagnosed up to or later than 15 years the corresponding risks in their offspring were $2.0 \pm 0.8$ and $2.5 \pm 0.9 \%$, respectively, $(p=0.9)$.

Using the life-table method we were not able to confirm previous findings of an increased risk of IDDM in offspring born to IDDM affected mothers younger than 25 years compared to those born to older mothers (data not shown).

The multivariate analysis of several variables that might influence the cumulative recurrence risk of diabetes in the offspring of diabetic parents was carried out separately on offspring of male and female probands all diagnosed with IDDM before offspring birth (Table 4). These analyses revealed that the only significant predictor of IDDM recurrence risk in offspring whose parents were diabetic before time of offspring birth was paternal age of IDDM onset, i.e. IDDM recurrence risk in paternal offspring decreased by a factor of 0.94 per year of increasing paternal age of IDDM onset $(p=0.01)$. In the multivar- 


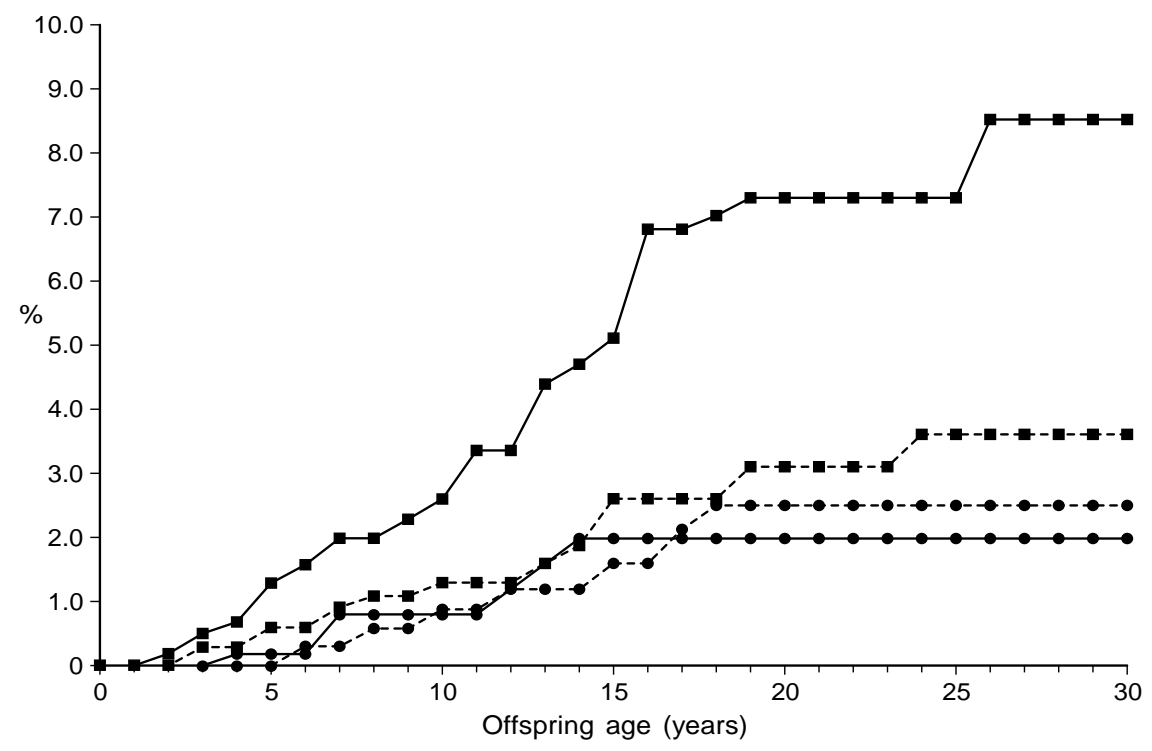

Fig. 2. Cumulative IDDM recurrence risk in offspring of IDDM parents (all diagnosed with IDDM before offspring birth) according to parental median age of IDDM onset

- Mother age at onset $\leq 15$ years (6794 obs. years, IDDM in 6)

-- Mother age at onset >; 15 years (7399 obs. years, IDDM in 7)

- Father age at onset $\leq 17$ years (8106 obs. years, IDDM in 27)

-- - Father age at onset $>17$ years (10760 obs. years, IDDM in 15)

$p=0.006$ for comparison of IDDM cumulative recurrence risks between offspring of male probands diagnosed before, rather than after age 17

iate analyses we found no significant influence of parental age at offspring birth, offspring current age, offspring gender or offspring birth order on the disease transmission, either in offspring of males or of females.

\section{Discussion}

The population-based data of this survey were obtained from 2726 adult Danish Caucasian IDDM patients characterised by a current age of 20-65 years and age at disease onset up to age 30 years. We found that the mean age of IDDM onset in the present proband population was significantly lower in female probands, which is in agreement with previous observations in epidemiological surveys, first in Pittsburgh, Pa., USA [24], of a large peak at puberty, occurring approximately 1 year earlier for females. This pattern of IDDM onset has since been seen in almost all populations where registries have been established, including the Danish population [13]. The observation also agrees with recent estimations of age- and sexspecific IDDM incidence rates in Denmark [25].

We observed a significantly decreased cumulative recurrence risk of IDDM in offspring of female probands compared to offspring of male probands, only

Table 4. Predictors of IDDM recurrence risk in offspring of parents all diagnosed with IDDM before offspring birth

\begin{tabular}{|c|c|c|c|c|c|c|}
\hline Proband related variables & $d f$ & parameter & SE & $\mathrm{RR}$ & $95 \% \mathrm{CI}$ & $p$-value \\
\hline $\begin{array}{l}\text { Offspring of male probands } \\
\text { Age at onset ( } 0-30 \text { years) } \\
\text { Age at offspring birth ( } 15-49 \text { years })\end{array}$ & $\begin{array}{l}1 \\
3\end{array}$ & $\begin{array}{r}-0.06 \\
0.05\end{array}$ & $\begin{array}{l}0.02 \\
0.04\end{array}$ & $\begin{array}{l}0.94 \\
1.05\end{array}$ & $\begin{array}{l}0.91-0.98 \\
0.97-1.14\end{array}$ & $\begin{array}{l}0.01 \\
0.15\end{array}$ \\
\hline $\begin{array}{l}\text { Offspring related variables } \\
\text { Offspring current age (years) } \\
\text { Gender (males vs females) } \\
\text { Birth order (increasing) }\end{array}$ & $\begin{array}{l}2 \\
4 \\
5\end{array}$ & $\begin{array}{l}0.04 \\
0.09 \\
0.02\end{array}$ & $\begin{array}{l}0.02 \\
0.31 \\
0.22\end{array}$ & $\begin{array}{l}1.05 \\
1.09 \\
1.02\end{array}$ & $\begin{array}{l}1.00-1.08 \\
0.60-2.01 \\
0.66-1.57\end{array}$ & $\begin{array}{l}0.06 \\
0.77 \\
0.92\end{array}$ \\
\hline $\begin{array}{l}\text { Offspring of female probands } \\
\text { Age at onset ( } 0-30 \text { years) } \\
\text { Age at offspring birth ( } 16-43 \text { years })\end{array}$ & $\begin{array}{l}4 \\
3\end{array}$ & $\begin{array}{r}0.02 \\
-0.09\end{array}$ & $\begin{array}{l}0.04 \\
0.09\end{array}$ & $\begin{array}{l}1.02 \\
0.91\end{array}$ & $\begin{array}{l}0.94-1.10 \\
0.77-1.31\end{array}$ & $\begin{array}{l}0.73 \\
0.33\end{array}$ \\
\hline $\begin{array}{l}\text { Offspring related variables } \\
\text { Offspring current age (years) } \\
\text { Gender (males vs females) } \\
\text { Birth order (increasing) }\end{array}$ & $\begin{array}{l}2 \\
5 \\
1\end{array}$ & $\begin{array}{l}0.02 \\
0.16 \\
0.58\end{array}$ & $\begin{array}{l}0.04 \\
0.56 \\
0.38\end{array}$ & $\begin{array}{l}1.02 \\
1.18 \\
1.79\end{array}$ & $\begin{array}{l}0.94-1.06 \\
0.39-3.52 \\
0.85-3.77\end{array}$ & $\begin{array}{l}0.71 \\
0.77 \\
0.28\end{array}$ \\
\hline
\end{tabular}

Multivariate analysis using the cox proportional hazards model (stepwise regression) 
if parents had been diagnosed with IDDM before offspring birth. Despite the large size of the total offspring population, the subpopulation of offspring whose parents developed IDDM after offspring birth only comprised 14 IDDM cases. Thus, this observation needs to be confirmed in a larger population including more offspring of parents diagnosed with IDDM after offspring birth. Our findings however, suggest that genetic susceptibility to IDDM might be modified by certain aspects of diabetic pregnancies. This supports the hypothesis first proposed by Warram et al. [3] that a mechanism for this apparently protective maternal effect might be that exposure to diabetes in utero can protect a fetus from developing IDDM later in life by induction of mechanisms similar to immunological tolerance to autoantigens of beta cells. Although Warram et al. [18] in their study on self-reported data did not find a correlation between selective loss of diabetes-susceptible fetuses in perinatal deaths or spontaneous abortions and the IDDM risk in the surviving offspring, a mechanism of selective loss of genetically susceptible fetuses through early spontaneous abortions and failures in implantation in mothers with IDDM may exist. In contrast with the recent Finnish study [6] we found no sex difference in the IDDM prevalence and recurrence risk among sons and daughters of IDDM affected parents of a given sex, thus our observations are consistent with the genetic imprinting hypothesis [17]. This has to be further explored in future genetic epidemiological studies. We found that the number of offspring is significantly reduced for probands diagnosed with IDDM before having their first offspring compared to probands diagnosed after the birth of the youngest offspring. This might be due to reduced fertility in IDDM patients, IDDM complications, abortions or a voluntary choice as part of family planning. However since the IDDM recurrence risk is calculated as the number of IDDM cases per total number of offspring observation years and the potential diabetic status of an unborn offspring is notknown, the recurrence risk is unlikely to be influenced by these differences. In addition, we have restricted the multivariate analyses to the 2380 offspring whose parents were all diagnosed with IDDM before offspring birth in order to avoid a possible confounding from differences in parental IDDM status at the time of pregnancy.

The finding that the offspring IDDM risk is associated with paternal age at IDDM onset partly agrees with the findings of a study from the Joslin Diabetes Clinic [5] reporting the highest IDDM recurrence risk in offspring of both fathers and mothers diagnosed with IDDM before age 11 years. However, another recent study from this clinic [4] reported in contrast to our findings that the risk among offspring of IDDM fathers did not vary according to the fathers age of diagnosis although they found that the risk in maternal offspring was only significantly lower than the risk in paternal offspring if the mothers had been diagnosed before age 8 years. The mechanisms responsible for different recurrence risks of IDDM in offspring according to age at diagnosis in parents are matters of speculation but genetic factors may play a role. It is well established that among Caucasians the HLA class II DR 3,4 phenotype is significantly more frequent in IDDM patients with early disease onset $[26,27]$. None of the above-mentioned epidemiological studies were stratified for genetic components or for gender. In a recent study [28] evidence for a new IDDM susceptibility locus, IDDM15, was found. Interestingly, IDDM15 is linked to HLA in male, but not female meiosis [28]. Thus, it can be speculated that IDDM fathers with young age at onset are more likely to transmit high-risk haplotypes, e.g. including both HLA and IDDM15 high-risk alleles, to their offspring than mothers with IDDM due to linkage of non-MHC susceptibility loci to HLA.

The present study is in agreement with the findings from a recent nationwide Finnish study [6] unable to confirm earlier findings from the Joslin Diabetes Clinic $[4,5,19]$ that the risk of IDDM was increased in offspring of diabetic mothers who gave birth before age 25 years compared to those who gave birth after age 25 years.

In contrast to the Finnish study [6] neither offspring gender nor offspring birth-order were significant predictors of offspring IDDM recurrence risk in our study.

In conclusion, this large Danish population-based survey confirmed previous observations that the cumulative recurrence risk of IDDM in offspring of IDDM affected mothers is significantly decreased compared to the risk in offspring of IDDM affected fathers. This difference was seen only in offspring of probands with IDDM at the time of offspring birth. However, this observation has to be confirmed in a larger population. We found that among the several biologic variables tested separately on offspring of male and female probands all diagnosed with IDDM before the time of offspring birth, paternal age at IDDM onset was the only significant predictor of IDDM recurrence risk in offspring.

The predictors of IDDM recurrence risk identified from the present population may be important for counselling families in which one parent has IDDM and should be investigated further in even larger population-based epidemiological and genetic studies.

Acknowledgements. Members of the Danish IDDM Epidemiology and Genetics Group are acknowledged for their contribution to the present study: Bernhard Enk, Nykøbing Falster; Finn Mølgaard Hansen, Næstved; Henning Juhl, Slagelse; Henning Bækgaard Laursen, Kalundborg; Karsten Sølling, Holbæk; Steen Vadstrup, Nykøbing Falster. Secretaries and nurses from the participating medical departments and outpatient clinics are greatly appreciated for their help in identifying the IDDM patients for the study: Anni Bjergstrøm, Køge; Else 
Marquardsen, Steno Diabetes Center; Kirsten Jørgensen, Hørsholm; Aase Mikkelsen, Nykøbing Falster. Janice Dorman, Associated Professor of Diabetes Epidemiology and Ann Steenkiste, Biostatistician, Graduate School of Public Health, University of Pittsburgh, Pa. USA are acknowledged for their valuable scientific assistance.

This study was financially supported by the Danish Diabetes Association through a Research Grant, the Danish Medical Research Grant, the region - 3 fund and by The Danish Medical Research Council through Research Grant 9600075. The Danish Medical Research Council also offered biostatistical assistance.

Dr. J. Johannesen and Dr. O.P. Kristiansen are recipients of Research Grants from the University of Copenhagen.

\section{References}

1. Degnbol B, Green A (1978) Diabetes mellitus among first and second-degree relatives of early onset diabetics. Ann Hum Genet 42: 25-47

2. Tillil H, Köbberling J (1982) Age-corrected empirical genetic risk estimates for first degree relatives of IDDM patients. Diabetes 36: 93-99

3. Warram J, Krolewski AS, Gottlieb M, Kahn CR (1984) Differences in risk of insulin-dependent diabetes mellitus in offspring of diabetic mothers and diabetic fathers, $\mathrm{N}$ Engl J Med 311: 149-151

4. Bleich D, Polak M, Eisenbarth GS, Jackson RA (1993) Decreased risk of Type 1 diabetes in offspring of IDDM in offspring of an IDDM parent. Diabetes 44: 295-299

5. El-Hashimy M, Angelico MC, Blaise C, Krolewski AS, Warram JH (1995) Factors modifying the risk of mothers who acquire diabetes during adrenarchy. Diabetes 42: 1433-1439

6. Tuomilehto J, Podar T, Tuomilehto-Wolf E, Virtala E (1995) Evidence for importance of gender and birth cohort for risk of IDDM in offspring of IDDM parents. Diabetologia 38: 975-982

7. Lorenzen T, Pociot F, Hougaard P, Nerup J (1994) Longterm risk of IDDM in first degree relatives of patients with IDDM. Diabetologia 37: 321-321

8. Todd JA, Farral M (1996) Panning for gold: genome-wide scanning for linkage in type 1 diabetes. Hum Mol Genet 5: 1443-1448

9. Pociot F (1996) Insulin-dependent diabetes mellitus - a polygenic disorder ? Dan Med Bull 43: 216-248

10. Pociot F, Mandrup Poulsen T (1997) Aetiology and pathogenesis of insulin-dependent diabetes mellitus: general overview. In: Leslie RDG (ed) Molecular pathogenesis of diabetes mellitus, vol 22. Karger, Basel, pp 1-22

11. Cristau B, Kromann H, Cristy M, Andersen OO, Nerup J (1979) Incidence of insulin dependent diabetes mellitus (0-29 years at onset) in Denmark). Acta Med Scand [Suppl] 624: 54-60

12. Mølbak AG, Christau B, Marner B, Borch-Johnsen, Nerup $\mathrm{J}$ (1994) Incidence of diabetes mellitus in age groups over 30 years in Denmark. Diabet Med 1: 650-655
13. Pociot F, Nørgård K, Hobolth $\mathrm{N}$, Andersen $\mathrm{O}$, Nerup J and The Danish Study Group of Diabetes in Childhood (1993) A nationwide population-based study of the familial aggregation of insulin-dependent diabetes in Denmark. Diabetologia 36: $870-875$

14. Dahlquist G, Blom L, Tuvemo T, Nyström L, Sandström A, Wall S (1989) The Swedish childhood diabetes study - results from a nine year case register and a one year case-referrent study indicating that type 1 (insulin-dependent) diabetes mellitus is associated with both type 2 (non-insulindependent) diabetes mellitus and autoimmune disorders. Diabetologia 32: 2-6

15. Tuomilehto J, Lounamaa R, Tuomilehto-Wolf E et al. (1992) Epidemiology of childhood diabetes mellitus in Finland - background of a nationwide study of type 1 (insulindependent) diabetes mellitus. Diabetologia 35: 70-76

16. O'Leary LA, Dorman J S, LaPorte R et al. (1991) Familial and sporadic insulin-dependent diabetes: evidence for heterogenious etiologies? Diabetes Res Clin Pract 14: 183-190

17. McCarthy BJ, Dorman JS, Aston CE (1991) Investigating genomic imprinting and susceptibility to insulin-dependent diabetes mellitus: an epidemiological approach. Genet Epidemiol 8: 177-186

18. Warram H, Krolewski AS, Kahn CR (1988) Determinants of IDDM and perinatal mortality in children of diabetic mothers. Diabetes 37: 1328-1334

19. Warram JH, Martin BC, Krolewski AS (1991) Risk of IDDM in children of diabetic mothers decreases with increasing maternal age at pregnancy. Diabetes 40: 1679-1684

20. MJ Khoury, TH Beaty, BH Cohen (1993) Fundamental epidemiologic concepts and approaches. In: (eds) Fundamentals of genetic epidemiology. Oxford University Press, New York Oxford, p 73

21. (1995) Statistical Yearbook. Danmarks Statistik, Copenhagen

22. Pedersen J (1977) The pregnant diabetic and her newborn, 2nd edn. Munksgård, Copenhagen, pp 72-80

23. Mølsted-Pedersen J, Kuhl C (1986) Obstetrical management in diabetic pregnancy: the Copenhagen experience. Diabetologia 29: 13-16

24. LaPorte RE, Tajima N, Dorman JS et al. (1986). Differences between blacks and whites in the epidemiology of insulin-dependent diabetes mellitus in Allegheny county, Pennsylvania. Am J Epidemiol 123: 592-603

25. Green A, Gale EAM, Patterson CC , The EURODIAB ACE Study Group (1992) Incidence of childhood-onset insulin dependent diabetes mellitus: The EURODIAB ACE Study. Lancet 339: 905-909

26. Svejgaard A, Jakobsen K, Platz P et al. (1986) HLA associations in insulin-dependent diabetes: search for heterogeneity in different groups of patients from a homogeneous population. Tissue Antigens 28: 237-244

27. Caillat-Zucman S, Garchon HJ, Timsit J et al. (1992) Agedependent HLA genetic heterogeneity of type 1 insulin-dependent diabetes mellitus. J Clin Invest 90: 2242-2250

28. Deléphine M, Pociot F, Habita C et al. (1997) Mapping of a new non-HLA susceptibility locus for type 1 diabetes on chromosome 6, linked to HLA. Am J Hum Genet 60: 174-187 